\title{
Cytotoxic effect of naphthalene on root meristem of Allium cepa L.
} Bhaskar Sarma ${ }^{1 *}$, Dipika Kapil ${ }^{1}$, Bhaben Tanti ${ }^{2}$

${ }^{1}$ Genetics and Plant Breeding laboratory, Department of Botany, Bodoland University, Kokrajhar, Assam, India ${ }^{2}$ Genetics and Plant Breeding laboratory, Department of Botany, Gauhati University, Guwahati 781014, Assam, India.

Received: January 18, 2017; Accepted: February 21, 2017

\begin{abstract}
The cytotoxic effect of naphthalene was assessed in the root meristem of Allium cepa L. - a model plant for chromosomal study. The newly emerging roots were treated with $10 \%, 30 \%, 50 \%, 75 \%$ and $100 \%$ naphthalene solution (v/v). Each treatment was kept for 6, 12, 18, 24 and 48 hours respectively to study their cytotoxic effect. Naphthalene exerted depressive effects on mitosis, including reduced mitotic indices and accumulation of abnormal mitotic phases. The mitotic index showed decreasing tendency with parallel increase in naphthalene concentrations. Sticky metaphase, C- metaphase, diagonal metaphase, nuclear disintegration were found to be in higher frequency in all treatments. Both duration and concentration of the treatment influenced the cell division.
\end{abstract}

Key words: Naphthalene; Allium cepa L.; chromosomal aberrations; mitotic index

\section{Introduction}

Naphthalene is the simplest of the aromatic hydrocarbons with more than one ring (polycyclic hydrocarbons), effectively it is two benzene rings fused together. Naphthalene is traditionally derived from coal tar, white or colorless with chemical formula $\mathrm{C}_{10} \mathrm{H}_{8}$ and molecular weight is $128.6 \mathrm{~g} / \mathrm{mol}$.

Naphthalene has been used as a household fumigant. In a sealed container containing naphthalene pellets, naphthalene vapors build up to levels toxic to both the adult and larval forms of many moths that attack textiles. Other fumigant uses of naphthalene include use in soil as a fumigant pesticide, in attic spaces to repel animals and insects, and in museum storage drawers and cupboards to protect the contents from attack by insect pests.

Naphthalene enters the environment from industrial uses. Most of the naphthalene entering the environment is from the burning of woods and fossil fuels in the home. The second greatest release of naphthalene is through the use of moth repellents. Only about $10 \%$ of the naphthalene entering the environment is from coal production and distillation. Less than $1 \%$ of the naphthalene released to the atmosphere can be attributed to the losses from naphthalene production. Cigarette smoking also releases small amounts of naphthalene into the air. Naphthalene evaporates easily. Naphthalene can change to 1- naphthol or 2- naphthol. These chemicals have some of the toxic properties. It becomes gas when exposed to air and cause that pungent moth ball smell. These gases are irritating to the eyes and lungs and may cause headache, dizziness and nausea. Exposure to naphthalene mothballs can cause acute haemolysis (anemia) in people. International

\section{${ }^{*}$ Corresponding Author:}

Dr. Bhaskar Sarma,

Genetics and Plant Breeding laboratory,

Department of Botany, Bodoland University,

Kokrajhar, Assam, India.

E-mail: bhaskarsarma252@gmail.com
Agency for Research on Cancer (IARC) classifies naphthalene as possibly carcinogenic to humans and animals. IARC points out that acute exposure causes cataracts in humans, rats, rabbits, and mice. Chronic exposure to naphthalene vapors is reported to also cause cataract and retinal hemorrhage.

Naphthalene causes nausea, vomiting, abdominal pain, and anemia. Testing at one home following the incident indicated an airborne naphthalene concentration of 20 $\mathrm{ppb}\left(\mathrm{mg} / \mathrm{m}^{3}\right)$. Symptoms abated after removal of the mothballs. Workers occupationally exposed to naphthalene fumes or dust for up to five years was studied for adverse ocular effects (Ghetti and Mariani, 1956). Multiple pin-point opacities developed in 8 of 21 workers. Vision did not appear to be impaired. Cataracts and retinal hemorrhage were observed in a 44-year-old man occupationally exposed to powdered naphthalene, and a co-worker developed chorioretinitis (Van der Hoeve, 1906). Ingestion of naphthalene mothballs is a frequent cause of accidental poisoning of children (Siegel and Wason, 1986). Deaths have been reported following ingestion of naphthalene mothballs. A 17-year old male ingested mothball, developed gastrointestinal bleeding, hematuria, and coma, and died after five days (Gupta et al., 1979). A 30-year old female ingested 30 mothballs and died after five days (Kurz, 1987). Acute haemolytic anemia was reported among 21 infants exposed to naphthalene vapours from nearby mothballtreated materials (Valaes et al., 1963). Increased serum bilirubin, methemoglobin and fragmented red blood cells were observed. A 69-year-old female developed aplastic anemia two months after several weeks' exposure to naphthalene (Harden and Baetjer, 1978). Exposure to a large amount of naphthalene may damage

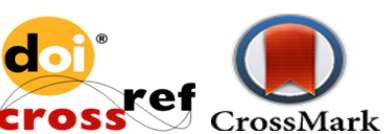


or destroy some of red blood cells. This could cause to have too few red blood cells until body replaces the destroyed cells. This problem is called hemolytic anemia. People, particularly children, have developed this problem after eating naphthalene containing mothballs or deodorant blocks.

Laboratory rabbits, guinea pigs, mice, and rats sometimes develop cataracts (cloudiness) in their eyes after swallowing naphthalene at high dose levels. When mice or rats breathed in naphthalene vapors daily throughout their lives (2 years), cells in the lining of their noses or lungs were damaged. Some exposed female mice also developed lung tumors. Some exposed male and female rats developed nose tumors. When mice or rats were fed naphthalene in their food for 13 weeks, no tumors or other tissue changes were found. The only effect found was decreased body weight in rats that were fed naphthalene. Based on these results from animal studies, the U.S. Department of Health and Human Services concluded that naphthalene is reasonably anticipated to be a human carcinogen. The International Agency for Research on Cancer (IARC) concluded that naphthalene is possibly carcinogenic to humans, because there is enough evidence that naphthalene causes cancer in animals. Under the EPA 1986 cancer guidelines, naphthalene was assigned to Group C possible human carcinogen.

The available database for naphthalene genotoxicity is extensive and has been reviewed recently by IARC (2002). Schreiner (2003) suggests that, naphthalene is not mutagenic to bacteria or mammalian cells in culture, but does produce toxicity-dependent secondary damage to DNA at excessive concentrations. Evidence for the secondary damage is seen as DNA fragmentation in vivo, as well as sister chromatid exchange (SCE) and chromosome breakage in vitro. Schreiner concludes that the DNA fragmentation and chromosome breakage events are consistent with a threshold-related cytotoxicity mechanism of tumor induction, driven by cytotoxicity and cell regeneration leading eventually to tumor development. Scientific statements with a high degree of certainty under conditions employed in the NTP bioassays, naphthalene induces respiratory tumors in rodents only at sites showing signs of significant cytotoxicity. The tumors in both species were strongly associated with chronic inflammation, hyperplasia, metastatic changes, and cell proliferation, all signs indicative of cytotoxicity.

A number of plant bioassay techniques have been developed for the detection of environmental mutagens because plant chromosomes are relatively large and respond to treatment with mutagens in a similar way to mammals and other eukaryotes (Grant, 1994; Satyavani et al., 2011). Among these assays, the Allium root meristems is routinely used for studying the effect of toxic materials on chromosomes and mitotic cell division and has been recommended as a standard assay for environmental monitoring (Fiskesjo, 1985).
In this present investigation, therefore, an attempt was made to find out the possible toxic effects of naphthalene on plant cells. Hence Allium cepa L. root meristem was used as an in vivo test system to evaluate the cytotoxicity of naphthalene.

\section{Material and Methods}

\section{Source of materials}

The bulbs of the common onion (Allium cepa L.) of similar sizes and weights were purchased from Debargaon, Kokrajhar district. The required apparatuses were beaker $(100 \mathrm{~mL}, 10 \mathrm{~mL})$, measuring cylinder (100 $\mathrm{mL}, 10 \mathrm{~mL}$ ), slide, cover slip, spirit lamp, blade, needle, bottles and Chemicals which includes naphthalene, aceto-orcein, glacial acetic acid, petroleum ether, distilled water, ethanol and para dichlorobenzene.

\section{Cytological studies}

Cytotoxic effect of naphthalene studies using Allium cepa L. as a test plant. The root meristems of Allium cepa $L$. consist of diploid $(2 \mathrm{n}=16)$ set of chromosomes. Clean and healthy bulbs of onion were chosen for each treatment group. Before starting the experiments, dry scales of bulbs were removed and then the onion bulbs were induced to root by placing them on glass of sandy soil with the base of the onion touching the surface of the soil at room temperature. When the roots grew upto $1.5-2.0 \mathrm{~cm}$ in length, they were cut and treated with, different concentrations of naphthalene solution of $10 \%, 30 \%, 50 \%, 75 \%$, and $100 \%(\mathrm{v} / \mathrm{v})$ dissolved in petroleum ether. Each concentration of naphthalene solution was kept for $(6,12,18,24$ and 48) hours respectively to study their cytotoxic effect. The root tips treated in distilled water was used as control. The root tips of control and experimental samples were thoroughly washed in distilled water pretreated with para-dichlorobenzene for four hours and then fixed in acetic acid ethanol (1:3) solution for $6 \mathrm{~h}$, washed them by $70 \%$ alcohol and preserved in $70 \%$ ethanol for slide preparation. The fixed root tips were heated gently for 2-3 min on a spirit lamp containing $1.5 \%$ aceto orcein solution and placed on a clean slide (Borah and Talukdar, 2002; Sharma and Sharma, 1980; Sarma and Tanti, 2015). The dark portions of root tip were cut with a blade and put a cover slip on the tip. Microscopic studies were done by the gentle pressing on the cover slip and taping it to disperse the cell and observed under microscope $\left(100_{\mathrm{x}}\right)$ and cells in mitosis were counted. Hereby, mitotic index (MI) was evaluated by analyzing at least 500 cells per treatment (Tanti et al., 2009). Chromosomal Abnormalities (CA) were calculated for each concentration and the values were expressed as mean $\pm \mathrm{SD}$. MI was calculated using following formula:

$$
M I=\frac{\text { Total number of cells in division }}{\text { Total number of cells observed }}
$$




\section{Results}

\section{Effect of naphthalene on mitotic index}

The cytotoxic effects of naphthalene on somatic onion Allium cepa L. cells were estimated on the basis of changes in mitotic index and other induced abnormalities. The mitotic index and percentage of abnormalities observed were presented in Table 1 . The mitotic index has declined as the concentration of naphthalene increased. The percentage of abnormalities, however, showed an opposite trend. The percentage of cell division and abnormalities induced varied in direct proportion to the naphthalene concentration and duration of exposure. Minimum cytotoxicity was observed in roots treated with naphthalene solution 10 $\%$ while maximum effect was obtained in roots treated with $100 \%$ solution. Naphthalene treated cells showed significant reduction in the frequency of mitotic index during all doses and durations when compared to control sets. This divisional frequency got reduced when dose and duration increased.

Effect of naphthalene on chromosome behavior The onion root tips treated with naphthalene solution in different concentrations showed various chromosome abnormalities such - enucleate cells, diagonal metaphase, nuclear disintegration, binucleate chromosome, sticky metaphase, C-metaphase, diagonal metaphase, syncytium formed in anaphase, multipolar anaphase, chromosome bridge of anaphase, resident chromosome in metaphase, nuclear lesion and fragmented prophase, precocious anaphasic chromosome, fragmentation (Fig. 1). The chromosomal aberrations observed in the treated cells were found to be of higher frequency during longer exposure. A distinct dose dependent increase in chromosomal anomalies was observed in all treatments. Sticky metaphase, C-metaphase, diagonal metaphase were found to be in higher frequency in all treatments. The frequency of nuclear disintegration was found to be higher during $6 \mathrm{~h}$ exposures where as in 12, 18, 24 and $48 \mathrm{~h}$ exposures, this was reduced. The abnormalities such as c-metaphase, reported to be induced by treatment with chemicals. Appearance of $\mathrm{C}$-metaphase is due to inactivation of the spindle apparatus leading to the delay in the division of the centromere. Appearance of stickiness of chromosomes at anaphase was encountered in all the cells treated with different concentrations of naphthalene. The frequency of sticky anaphase was more in cells treated with higher concentrations of naphthalene than those with lower concentrations. The stickiness of chromosome at anaphase caused inability of normal movement of the chromosomes at anaphase.

Table 1: Mitotic indices and chromosomal aberrations observed in Allium cepa root meristem treated with naphthalene

\begin{tabular}{ccccccc}
\hline $\begin{array}{c}\text { Concentration } \\
\text { of } \\
\begin{array}{c}\text { Naphthalene } \\
\text { (\%) }\end{array}\end{array}$ & $\begin{array}{c}\text { Duratio } \\
\mathbf{n}(\mathbf{h})\end{array}$ & $\begin{array}{c}\text { Total analysed } \\
\text { cells }\end{array}$ & $\begin{array}{c}\text { No of cells } \\
\text { showing } \\
\text { division }\end{array}$ & $\begin{array}{c}\text { Total } \\
\text { aberrant cells }\end{array}$ & $\begin{array}{c}\text { Mitotic index \% } \\
\text { (Mean } \pm \text { SD) }\end{array}$ & $\begin{array}{c}\text { Chromosomal } \\
\text { aberrations } \\
\text { (Mean } \pm \text { SD) }\end{array}$ \\
\hline Control & & 1000 & 399 & 0 & 39.9 & -- \\
& 6 & 1000 & 392 & 5 & $39.2 \pm 2.16$ & $1.27 \pm 0.81$ \\
& 12 & 1000 & 387 & 7 & $38.72 \pm 2.16$ & $1.80 \pm 1.70$ \\
10 & 18 & 1000 & 379 & 8 & $37.9 \pm 2.88$ & $2.11 \pm 1.29$ \\
& 24 & 1000 & 374 & 10 & $37.4 \pm 2.16$ & $2.67 \pm 1.82$ \\
& 48 & 1000 & 370 & 11 & $37 \pm 2.08$ & $2.97 \pm 1.70$ \\
& 6 & 1000 & 395 & 13 & $39.5 \pm 2.94$ & $3.29 \pm 2.16$ \\
30 & 12 & 1000 & 389 & 15 & $38.9 \pm 2.16$ & $3.85 \pm 2.08$ \\
& 18 & 1000 & 378 & 16 & $37.8 \pm 1.70$ & $4.23 \pm 2.16$ \\
& 24 & 1000 & 367 & 17 & $36.5 \pm 2.16$ & $4.63 \pm 1.70$ \\
& 48 & 1000 & 361 & 20 & $36.1 \pm 1.63$ & $5.54 \pm 1.29$ \\
& 6 & 1000 & 389 & 21 & $38.9 \pm 2.16$ & $5.39 \pm 1.82$ \\
50 & 12 & 1000 & 380 & 23 & $38 \pm 3.55$ & $6.05 \pm 3.30$ \\
& 18 & 1000 & 373 & 24 & $37.3 \pm 2.16$ & $6.43 \pm 1.70$ \\
& 24 & 1000 & 370 & 26 & $37 \pm 2.08$ & $7.02 \pm 1.29$ \\
& 48 & 1000 & 363 & 28 & $36.3 \pm 1.63$ & $7.71 \pm 2.16$ \\
& 6 & 1000 & 376 & 29 & $37.6 \pm 2.62$ & $7.71 \pm 2.16$ \\
& 12 & 1000 & 362 & 31 & $26.2 \pm 2.16$ & $8.56 \pm 1.70$ \\
& 18 & 1000 & 358 & 32 & $35.8 \pm 1.29$ & $8.93 \pm 2.08$ \\
& 24 & 1000 & 354 & 34 & $35.4 \pm 1.82$ & $9.60 \pm 1.63$ \\
& 48 & 1000 & 341 & 36 & $34.1 \pm 1.29$ & $10.55 \pm 2.16$ \\
& 6 & 1000 & 354 & 38 & $35.4 \pm 9.74$ & $10.73 \pm 2.62$ \\
& 12 & 1000 & 232 & 39 & $23.2 \pm 0.08$ & $16.81 \pm 1.70$ \\
& 18 & 1000 & 211 & 40 & $21.1 \pm 1.29$ & $18.95 \pm 1.29$ \\
& 24 & 1000 & 209 & 42 & $20.9 \pm 1.70$ & $20.09 \pm 1.70$ \\
& 48 & 1000 & 197 & 43 & $19.7 \pm 0.95$ & $21.82 \pm 2.16$ \\
\hline
\end{tabular}


Fig 1: Chromosome abnormalities in the various phases of mitotic cell division of naphthalene solution treated onion root tips.
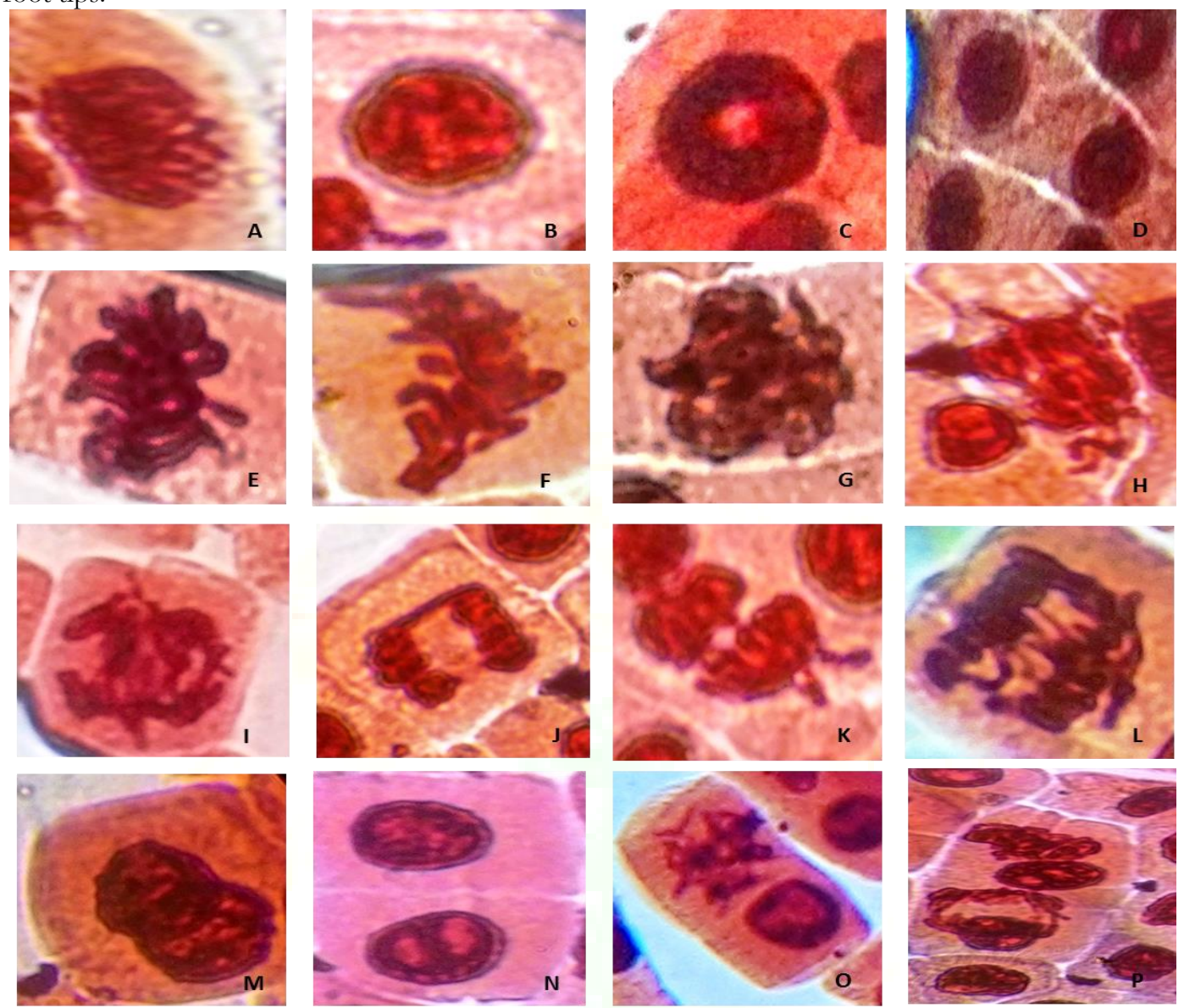

A. Diagonal metaphase; B-C. nuclear disintegration; D. binucleate chromosome; E. sticky metaphase; F. C metaphase; G. diagonal metaphase; H. syncytium formed in anaphase; I. multipolar anaphase; J- L. chromosome bridge of anaphase; K. sticky anaphase; M. Resident chromosome in metaphase; N. nuclear lesion and fragmented prophase; O. Precocious anaphasic chromosome; P. fragmentation.

\section{Discussion}

The increasing discharge of hazardous chemicals into the environment has affected the balance of natural ecosystems and has drawn attention of several researchers and governmental agencies to the health of living organisms (Leme et al., 2009). Higher plants that make them excellent genetic models to assess environmental pollutants, being frequently used in monitoring studies. The chemical mutagens cause damage in organisms when exposed, making possible to assess genetic end points from point mutations to chromosome damage in cells of several organs, tissues of leaves, roots and pollen (Grant, 1978).

The available database for naphthalene genotoxicity is extensive and has been reviewed that naphthalene is not mutagenic in the most commonly used tests to measure genotoxicity. Naphthalene is not mutagenic to bacteria or mammalian cells in culture, but does produce toxicitydependent secondary damage to DNA at excessive concentrations. Evidence for the secondary damage is seen as DNA fragmentation in vivo, as well as sister chromatid exchange (SCE) and chromosome breakage in vitro. DNA fragmentation and chromosome breakage events are consistent with a threshold-related cytotoxicity mechanism of tumour induction, driven by cytotoxicity and cell regeneration leading eventually to tumour development. Scientific statements with a high degree of certainty under conditions employed in the NTP bioassays, naphthalene induces respiratory tumours in rodents only at sites showing signs of significant cytotoxicity. The tumours strongly associated with chronic inflammation, hyperplasia, metastatic changes, and cell proliferation, all signs indicative of cytotoxicity.

In the present preliminary toxicity assay, treatments with $(10,25,50,75$ and 100$) \%$ of naphthalene produced a dose and duration-dependent mitotic index and chromosomal abnormalities in onion root meristems. The cytotoxic effects of naphthalene on somatic onion cells were estimated on the basis of changes in mitotic index and other induced abnormalities. The reduction of mitotic index during all treatments clearly indicates the mito-depressive and cytotoxic effect of naphthalene. The high frequency of mitotic abnormalities such as sticky metaphase; C -metaphase; diagonal metaphase induced by naphthalene primarily reflects its effects on mitotic spindles, altering the orientation of chromosomes at various stages of the cell cycle. The root tips treated with naphthalene for $6 \mathrm{hrs}$ induced lowest percentage of abnormalities while highest 
percentage of abnormalities occurred in roots treated for 48 hrs. Borah and Talukdar (2002) have reported that higher concentration and longer duration of treatment of the castor seed extract depressed the mitotic index greatly. The naphthalene concentration in the range of $75-100 \%$ induced higher percentage of abnormalities and low mitotic index. The root tips treated with lower concentration of naphthalene however showed higher mitotic index and lower percentage of abnormalities. Enucleation in considerable number of cells was an interesting finding of the present work. Considerable number of cells showed unequal distribution of chromosomes that might be attributed to abnormality in spindle formation causing unequal distribution of chromosomes. Treatments of cells with $75 \%$ and $100 \%$ naphthalene produced cells showing nuclear disintegration. This aberration might have developed due to breaking of the nucleus. The nucleus gradually disappeared from the cytoplasm.

Observation of chromosome stickiness is another type of abnormality induced by naphthalene. Stickiness is due to the inhibition of spindle formation (Amer and Ali, 1986). Improper folding of chromosome fibres that makes the chromatids connected by sub-chromatid bridges lead to form sticky chromosomes (McGill et al., 1974). The stickiness of chromosomes was also reported in cells treated with organophosphorus pesticides and industrial effluent.

The induction of chromosomal breaks by naphthalene indicates the clastogenic potential of the test chemical, which may lead to a loss of genetic material and these have been regarded as an indication of mutagenicity of the inducers (Raun et al., 1992). Precocious chromosomes is the result of unequal spindle movement in which some chromosome arms are pulled towards the extremity of the pole (Pathak, 1999) or it might have been caused by stickiness of chromosomes (Kaur and Grover, 1985).

\section{Conclusion}

Higher concentration and longer duration of naphtahalene treatment is toxic to cells. This study showed mitodepressive effect even in lower concentrations. The present study revealed cytotoxic and clastogenic properties of naphthalene. On the basis of the results it may be concluded that naphthalene is capable of inducing variety of cell abnormalities. Number of structural aberrations observed in the present study also indicated that naphthalene acted as potential mutagenic agents. Therefore, it is necessary that in addition to routine physico-chemical and biological analyses, the industrial effluents should also be evaluated for the cytological damages caused by naphthalene to plant cells.

\section{References}

1. Amer, S.M and E. M. Ali. Cytological study of insectide dichlorvor on the mitosis of Vicia faba. Cytologia., 51, (1986): 21-25.
2. Borah, S.P., and J. Talukdar. Studies on the cytotoxic effect of extract of castor seed Ricinus communis L. Cytologia., 67, (2002):235-243.

3. Fiskesjo, G. The Allium test as a standard in environmental monitoring. Hereditas., 102, (1985):99-112.

4. Ghetti, G and L. Mariani. Eye changes due to naphthalene. Med. Lav., 47, (1956): 533-538.

5. Grant, W.F. Chromosome aberrations in plants as a monitoring system. Environ. Health Perspectives, 27, (1978): 37- 43.

6. Grant, W. F. The present status of higher plant bioassay for the detection of environmental mutagens. Mut. Res., 310, (1994):175-185.

7. Gupta, R., P. C. Singhal and M. A. Muthusethupathy. Cerebral oedema and renal failure following naphthalene poisoning. J. Assoc. of Physicians Ind., 27, (1979):347-348.

8. Harden, R. A and A. M. Baetjer. Aplastic anaemia following exposure to paradichlorobenzene and naphthalene. J. Soc. Occup. Med., 20, (1978):820-822.

9. Hore P, Tanti B. Karyomorphological Studies of Two Morphotypes of Lasia spinosa (Lour.) Thwaites Avaiable in Assam, India. Annals of Plant Sciences, 3, (2014), 792-796

10. Kaur, P. and I. S. Grover. 1985. Cytological effects of some organophosphorous insecticides on the root meristem of barley (Hrodeum vulgare L.). Cytologia, 50 (1985):187-197.

11. Kurz, J. M. 1987. Naphthalene poisoning: critical care nursing techniques. Dimensions of Critical Care Nurs. 6, (1987):264-270.

12. Leme, D. M. and M. A. M. Morales. 2009. Allium cepa test in environmental monitoring. A review on its application. Mut. Res. 68, (2009): 71-81.

13. McGill, M., S. Pathak and T.C. Hsu. 1974. Effect of Ethidium Bromide on mitosis and chromosome. Cytologia. 47, (1974): 157-167.

14. Pathak, G.P. 1999. Study of mitotic activity and chromosomal behaviour on carmoisine treated root meristem of Allium cepa L. M.Sc. Dissertation submitted to Central Department of Botany, Tribhuvan University, Kathmandu, Nepal

15. Raun, C., and J. Lilum. Application of micronucleus test in Vicia faba root tips in the rapid detection of mutagenic environmental pollutants. Chi. J. Environ. Sci. 4, (1992):5658.

16. Sarma, B and Tanti, B. Karyomorphology of three species of Aristolochia - Rare and Endemic Medicinal Plants of Assam, India. Caryologia: Int. J. Cytol. Cytosyst. Cytogen. (Taylor \& Francis). 68, (2015):154-158.

17. Sarma, B and Tanti, B. Karyomorphological Study of Stephania hernandifolia - A Rare Medicinal Plant from Assam, India. Annals of Plant Sciences. 3, (2014): 869-872 
18. Satyavani, S. K., T. Ramanathan and Gurudeeban. Plant mediated synthesis of biomedical silver nanoparticles by using leaf extract of Citrullus colocynthis. Res. J. Nanosci. and Nanotechnol. 1, (2011):95-101.

19. Schreiner, C.A. Genetic toxicity of naphthalene: a review. $J$ Toxicol Environ Health (B) Critic. Review. 6, (2003):161-83.

20. Sharma, A.K and A. Sharma. 1980), Chromosome techniques: Theory and practice Butterworths, London. 711

21. Siegel, E and Wason. 1986. Mothball toxicity. In the Pediatr Clinics of North America, Ed: Blumer, J L. and Reed, M.D. 33, (1986):369-374.

22. Tanti B, Buragohain AK, Dutta S, Gurung L, Shastry M, Borah SP. Studies on the cytotoxic effect of oil refinery sludge on root meristem. Advances in Environmental Biology, 3, (2009): 10-14.

23. Tanti B, Das AK, Kakati H, Choudhury D. Cytotoxic effect of silver-nanoparticles on root meristem of Allium sativum L. Journal of Research in Nanobiotechnol, 1, (2012): 1-8.
24. Toijam H, Borah SP, Tanti B, Borthakur SK. Karyomorphological studies in two species of Allium L. Journal of Research in Plant Sciences. 2, (2013): 213-221.

25. Valaes, T., S. A. Doxiadis and P. Fessas. Acute haemolysis due to naphthalene inhalation. J. Pediatric. 63, (1963): 904915.

26. Van der Hoeve, J. Chorioretinitis in humans from the effects of naphthalene. Archiv Augenheilkd. 56, (1906):259262

\section{Cite this article as:}

Bhaskar Sarma, Dipika Kapil \& Bhaben Tanti. Cytotoxic effect of naphthalene on root meristem of Allium cepa L. Annals of Plant Sciences 6.02 (2017): 1579-1584.

DOI: http://dx.doi.org/10.21746/aps.2017.03.001 